\title{
Prilocaine-Induced Methemoglobinemia
}

\author{
Alpay Medetalibeyoğlu ${ }^{a} \quad$ Elif Sitre Koç ${ }^{b} \quad$ Oyku Beyaz ${ }^{b} \quad$ Ahmed Edizer $^{a}$ \\ aDepartment of Internal Medicine, Medical Faculty, Istanbul University, Istanbul, Turkey; \\ bDepartment of Internal Medicine, Acıbadem Mehmet Ali Aydınlar University School of \\ Medicine, Istanbul, Turkey
}

\section{Keywords}

Cyanosis $\cdot$ Methemoglobinemia $\cdot$ Dyspnea $\cdot$ Bone marrow $\cdot$ Methylene blue

\begin{abstract}
Local anesthetics are used to anesthetize surface areas in several procedures. The history of anesthesia exposure has been established as an important factor for correct diagnosis. When they are used excessively, some systemic side effects such as methemoglobinemia, respiratory failure, cardiovascular arrhythmias, or neurological manifestations may occur. Methemoglobinemia which usually presents with nonspecific symptoms is a serious entity. It is a rare but severe side effect of anesthetics. We herein present a case of methemoglobinemia due to local anesthesia with prilocaine.

\section{Introduction}

Prilocaine, a local anesthetic agent, is generally used to reduce pain in surgical procedures working reversibly by blocking peripheral nerve conduction [1]. Due to its extensive use, the clinicians must be aware of possible side effects. Although systemic absorption of topical anesthetics is restricted, their systemic toxicities, including methemoglobinemia and respiratory symptoms, have been reported [2,3]. Methemoglobinemia, which is a rare and life-threating cause of hypoxemia, can occur secondary to the use of anesthetics [4]. Methemoglobinemia is a form of hemoglobin which contains iron that has been oxidized to the ferric $\left(\mathrm{Fe}^{+3}\right)$ state leading to rapid oxygen desaturation. 


\section{Case Report}

A 42-year-old female patient with a history of Familial Mediterranean Fever and pancytopenia was admitted to our emergency department complaining of dyspnea. Before administration to our clinic, she underwent bone marrow biopsy to assess the cause of pancytopenia. Approximately $6 \mathrm{~h}$ after the procedure, the patient suddenly developed bluish discoloration of the hands and lips with shortness of breath. In her medical history, she was diagnosed with Familial Mediterranean Fever 30 years previously and was using colchicum. She was a nonsmoker and did not consume alcohol either.

The initial vital signs were the following: temperature $36.6 \mathrm{C}^{\circ}$, heart rate 68 beats $/ \mathrm{min}$, blood pressure $90 / 60 \mathrm{~mm} \mathrm{Hg}$, and respiratory rate 36 breaths/min. The oxygen saturation by pulse oximetry was $78 \%$ in room air. On physical examination, cyanosis was observed in the fingertips and perioral area (Fig. 1). The lungs were clear and heart sounds were normal. Neurological evaluation was intact. Her electrocardiogram showed normal sinus rhythm and chest X-ray did not reveal any abnormalities.

Oxygen treatment and saline infusion were initiated due to low blood pressure and low oxygen saturation. An arterial blood gas (ABG) analysis showed $\mathrm{pH}$ of 7.54, partial pressure of carbon dioxide $\left(\mathrm{PaCO}_{2}\right)$ of $31.3 \mathrm{~mm} \mathrm{Hg}$, partial pressure of oxygen $\left(\mathrm{PaO}_{2}\right)$ of $108 \mathrm{~mm} \mathrm{Hg}$, bicarbonate $\left(\mathrm{HCO}_{3}\right)$ of $28.5 \mathrm{mEq} / \mathrm{L}$, hemoglobin of $13.2 \mathrm{~g} / \mathrm{dL}$, and lactate of $1.8 \mathrm{mEq} / \mathrm{L}$. The patient was receiving oxygen with a mask while an arterial blood sample was taken. A methemoglobin level of $34.9 \%$ was also reported.

Complete blood count results were consistent with pancytopenia as follows: hemoglobin, $8.7 \mathrm{~g} / \mathrm{dL}$ (normal range (NR): 11.7-15.5 g/dL), leukocyte count, $3.02 \times 10^{3} / \mu \mathrm{L}$ (NR: $4.1-$ $11.2 \times 10^{3} / \mu \mathrm{L}$ ), and thrombocyte count, $62.6 \times 10^{3} / \mu \mathrm{L}$ (NR: $\left.160-390 \times 10^{3} / \mu \mathrm{L}\right)$. Biochemistry laboratory test results were normal except for high levels of CRP (7.17 mg/L, NR: 0-5 mg/L).

After obtaining methemoglobin level, the patient was diagnosed with prilocaine-induced methemoglobinemia and treated with methylene blue $1 \mathrm{mg} / \mathrm{kg}$ i.v. over $30 \mathrm{~min}$ instantly with vitamin C infusion. Due to persistent cyanosis despite respiratory support, consultation was made with the undersea and hyperbaric medicine department which suggested hyperbaric oxygen treatment.

Shortly after methylene blue administration, dyspnea and cyanosis were resolved and the repeat methemoglobin level was $2 \%$ (Fig. 2). She was referred to the hyperbaric oxygen treatment clinic for continuation of follow-up and treatment.

\section{Discussion}

Methemoglobinemia is a form of hemoglobin which contains iron that has been oxidized to the ferric $\left(\mathrm{Fe}^{+3}\right)$ state. Oxidation of iron atoms from the ferrous $\left(\mathrm{Fe}^{2+}\right)$ to the ferric $\left(\mathrm{Fe}^{3+}\right)$ state impairs hemoglobin binding oxygen and its transportation to tissues. In healthy individuals, methemoglobin comprises less than $1.5 \%$ of total hemoglobin by methemoglobin reductase, cytochrome b5 reductase, and nicotinamide adenine dinucleotide phosphate enzyme systems [5].

Methemoglobinemia can be congenital or acquired [6]. The congenital form is generally caused by enzyme deficiency which plays a role in maintaining methemoglobin levels. The more common acquired form is seen here. Foods, drugs including local anesthetics, nitrates, dapsone, and toxic agents may induce methemoglobinemia [7]. 
In addition to these causes, some predisposing factors promote oxidization to the ferric ion including drug overdose (number of drugs or excessive dose of one drug) and factors affecting dermal absorption [8].

To date, there are several case reports of methemoglobinemia due to prilocaine use. When we reviewed these case reports, most of the prilocaine use is by reason of preoperative medication and anesthesia for dental procedures. The only case report of prilocaine-induced methemoglobinemia in Turkey was reported following subcutaneous prilocaine injection for hair removal. In our case, prilocaine was used before bone marrow aspiration and biopsy procedures. This is the first case report of methemoglobinemia which occurred following administration of prilocaine in bone marrow aspiration. Our aim is to raise awareness regarding adverse effects of bone marrow aspiration not only during the main procedure but also during administration of local anesthesia.

In our report, prior to bone morrow biopsy the patient received prilocaine, which has been reported to be a cause of methemoglobinemia. Our patient had anemia (hemoglobin level: $8.7 \mathrm{~g} / \mathrm{dL}$ ), which is associated with a high risk of developing severe respiratory and cardiac symptoms. Although the exposure to an agent causing methemoglobinemia is clear, other medications and family history should also be questioned.

Clinical presentation depends on methemoglobin concentrations. Levels below $30 \%$ present with headache, dizziness, and anxiety, and improve spontaneously. At levels between 30 and 50\%, dyspnea, chest pain, and lethargy occur. Seizures and cardiac dysrhythmias that increase the risk of mortality may be observed at concentrations above $60 \%$, while levels higher than $80 \%$ are fatal [9].

The diagnosis can be quickly made by standard pulse oximetry and ABG sample. While methemoglobinemia is regarded as the diagnosis, pulse oximetry can be untrustworthy due to its mechanism, which depends on comparing how much light is absorbed by the blood. In $\mathrm{ABG}$ analysis, acidosis can present because of impaired tissue oxygenation [10]. In our report the lactate level was $1.8 \mathrm{mEq} / \mathrm{L}$ with a $\mathrm{pH}$ of 7.54 , indicating alkalosis.

The treatment choice varies according to the symptoms and methemoglobin levels. While asymptomatic patients with methemoglobin concentrations less than $30 \%$ do not need methylene blue and may improve with oxygen therapy, methylene blue is indicated for symptomatic patients with higher concentrations. A dose of $1-2 \mathrm{mg} / \mathrm{kg}$ i.v. administered over 15-30 min is recommended. Moreover, high-dose ascorbic acid, exchange transfusion, and hyperbaric oxygen are additional therapies for selected patients [11-13]. Our patient was treated with methylene blue $1 \mathrm{mg} / \mathrm{kg}$ i.v. with vitamin C infusion; within $30 \mathrm{~min}$ her dyspnea and cyanosis resolved.

In summary, clinicians must be aware of the side effects of widely used medications. It is important to query the patient's medications in order to make the diagnosis. Severe adverse events can be prevented through early and adequate treatment.

\section{Statement of the Ethics}

The patient gave her written informed consent to publish her case (including publication of images). 
Disclosure Statement

The authors have no conflicts of interest to declare.

\section{Funding Sources}

The authors received no specific funding for this work.

\section{Author Contributions}

Alpay Alibeyoğlu: visualization, writing - review and editing. Elif Sitre Koç: resources, data curation, writer, critical review. Oyku Beyaz and Ahmed Edizer: data curation.

\section{References}

1 Lee HS. Recent advances in topical anesthesia. J Dent Anesth Pain Med. 2016 Dec;16(4):237-44.

2 Shamriz O, Cohen-Glickman I, Reif S, Shteyer E. Methemoglobinemia induced by lidocaine-prilocaine cream. Isr Med Assoc J. 2014 Apr;16(4):250-4.

3 Caré W, Larabi IA, Langrand J, Medernach C, Alvarez JC, Villa A. Poisoning associated with inappropriate use of a eutectic mixture of lidocaine and prilocaine before laser-assisted hair removal: about 3 cases. Int J Legal Med. 2019 May;133(3):843-6.

4 Guay J. Methemoglobinemia related to local anesthetics: a summary of 242 episodes. Anesth Analg. 2009 Mar;108(3):837-45.

5 Udeh C, Bittikofer J, Sum-Ping ST. Severe methemoglobinemia on reexposure to benzocaine. J Clin Anesth. 2001 Mar;13(2):128-30.

6 Abhilash KP. Methemoglobinemia: when to suspect and how to treat. Curr Med Issues. 2019;17(4):125-8.

7 Hegedus F, Herb K. Benzocaine-induced methemoglobinemia. Anesth Prog. 2005;52(4):136-9.

8 Kuiper-Prins E, Kerkhof GF, Reijnen CG, van Dijken PJ. 12-day-old boy with methemoglobinemia after circumcision with local anesthesia (lidocaine/prilocaine). Drug Saf Case Rep. 2016 Dec;3(1):12.

9 Harvey M, Cave G, Chanwai G. Fatal methaemoglobinaemia induced by self-poisoning with sodium nitrite. Emerg Med Australas. 2010 Oct;22(5):463-5.

10 Skold A, Cosco DL, Klein R. Methemoglobinemia: pathogenesis, diagnosis, and management. South Med J. 2011 Nov;104(11):757-61.

11 Bradberry S. Methemoglobinemia. Complications of poisoning. Medicine (Baltimore). 2012 Feb;40(2):59-60.

12 Grauman Neander N, Loner CA, Rotoli JM. The acute treatment of methemoglobinemia in pregnancy. J Emerg Med. 2018 May;54(5):685-9.

13 Cho Y, Park SW, Han SK, Kim HB, Yeom SR. A case of methemoglobinemia successfully treated with hyperbaric oxygenation monotherapy. J Emerg Med. 2017 Nov;53(5):685-7. 